\title{
Linear and Whorled Nevoid Hypermelanosis: A Rare Case Report
}

\section{Paras Choudhary ${ }^{1^{*}}$, Patki Anil $\mathrm{H}^{2}$ and Salunke Tejaswini ${ }^{3}$}

Department of Dermatology, Deenanath Mangeshkar Hospital, Pune, Maharashtra, India

*Corresponding author: Paras Choudhary, Department of Dermatology, Deenanath Mangeshkar Hospital, Pune, Maharashtra, 411009, Tel: 07665806560; E-mail address: paras2704@gmail.com

Received date: January 29, 2019; Accepted date: February 04, 2019; Published date: February 08, 2019

Copyright: $@ 2019$ Choudhary $\mathrm{P}$, et al. This is an open-access article distributed under the terms of the Creative Commons Attribution License, which permits unrestricted use, distribution, and reproduction in any medium, provided the original author and source are credited.

\begin{abstract}
Linear and Whorled Nevoid Hypermelanosis (LWNH) also known as 'zebra-like pigmentation' is characterized by linear and swirling streaks of hyperpigmentation along the Blaschko's lines without preceding inflammation and atrophy. It is mainly located on trunk and limbs. The hyperpigmentation may be present at birth or may develop by early childhood. Hyperpigmentation may progress for one to two years before stabilization. The eyes, palms, soles and mucus membrane are usually not affected. LWNH generally occurs sporadically. Very rarely, familial cases have been described.
\end{abstract}

Keywords: Linear and whorled nevoid hypermelanosis; Familial; Rare

\section{Introduction}

Linear and Whorled Nevoid Hypermelanosis (LWNH) is characterized by linear and swirling streaks of hyperpigmentation along the Blaschko's lines. It generally occurs sporadically. Very rarely, familial cases have been described. Here, we are reporting one such rare case of familial LWNH.

\section{Case Report}

A 19-year-old female presented to the outpatient department with her 2 sisters and mother with a complaint of dark-colored skin lesions over both lower limb for 15 years.

The lesions appeared over the lower leg at the age of 8 months and gradually progressed to involve both lower legs, thighs, and back by the age of 2 years followed by involvement of upper limb also (Figures 1 and 2). No history of preceding inflammation, blisters or atrophy was noted. Her palms, soles, and mucus membranes were not involved. No skeletal, cardiovascular, central and respiratory system involvement was observed. The girl was full term, normal and vaginally delivered. Growth and development have been normal. No history of consanguinity was present in the family. Over the past 5 years, she started noticing multiple hypopigmented lesions appearing over hyperpigmented streaks over the lower limb. No prior history of itching was present.

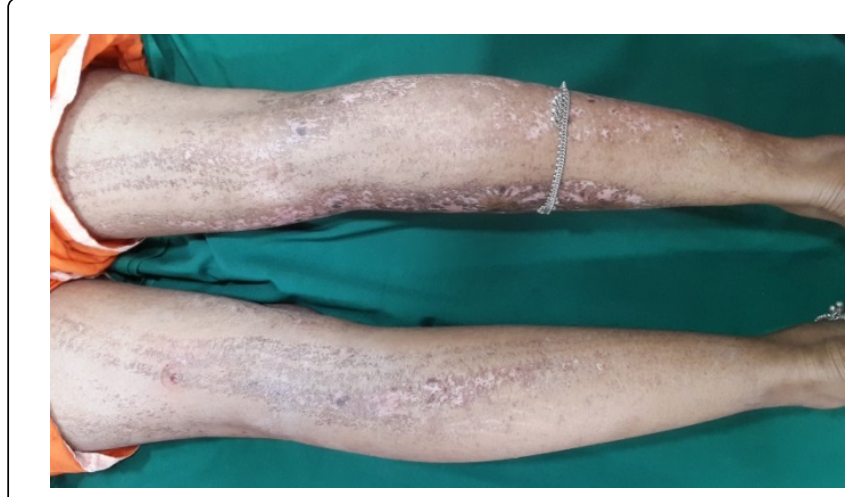

Figure 1: Girl-classical linear hyperpigmented streaks over the extensor surface of both lower limb.

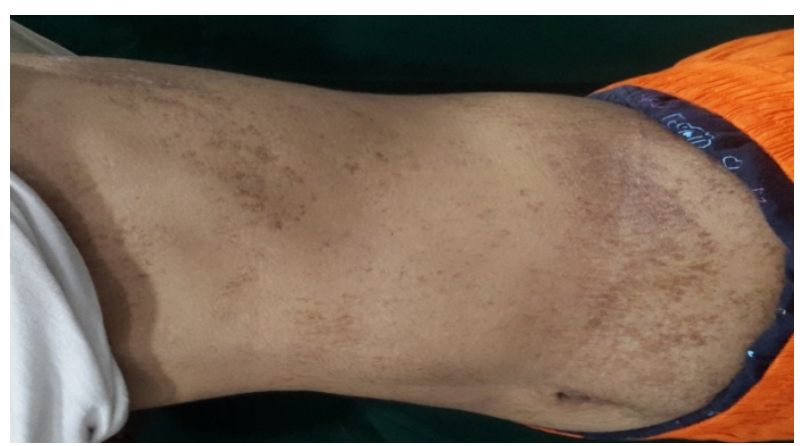

Figure 2: Girl-linear and whorled hyperpigmented streaks along the lines of blaschko over the trunk.

She had 3 elder sisters and one younger brother. Out of them, the eldest sister was unaffected. Two were affected, having similar hyperpigmented streaks over the upper limb since birth and out of them, one died because of unknown reason (Figure 3). Her brother was unaffected. 
Her mother also had similar hyperpigmented streaks over back and abdomen (Figure 4). They also gave a history of linear pigmented streaks in her maternal grandmother. Evidence of partial/complete repigmentation is also present in both mother and grandmother.

On cutaneous examination in the girl, multiple hyperpigmented macules and linear streaks arranged along the line of Blaschko on extensor aspects of both lower limb and upper limb were seen. In between the hyperpigmented streaks, multiple hypopigmented macules are also present. The overlying skin was normal and no clinical sign suggestive of Koebner phenomenon was visible.

All routine investigations were normal. No congenital abnormality was detected in X-ray, chest CT scan and 2D Echo. On histopathological examination, increased epidermal melanosis in the basal layer and a mild perivascular lymphocytic infiltrate was seen. No evidence of melanin pigment incontinence or melanophages was seen (Figure 5).

Based on clinicopathological correlation and history, a diagnosis of LWNH was made in all three successive family members. The family was reassured and counseled about the benign nature of the disorder. The periodic assessment was recommended to them. However, the exact reason of hypopigmentation is not clear.

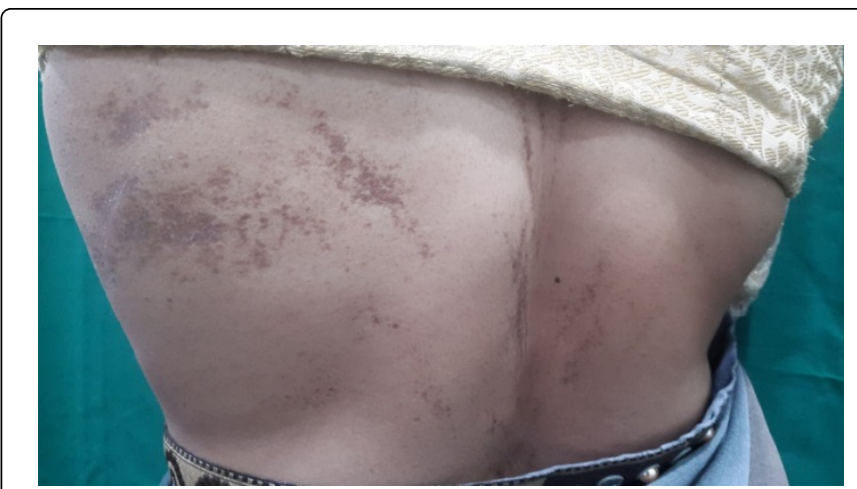

Figure 3: Sister-linear and whorled hyperpigmented streaks over the trunk.

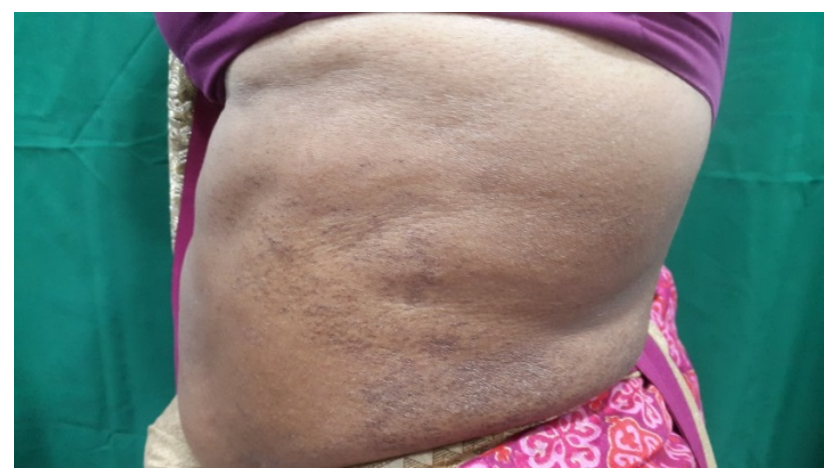

Figure 4:

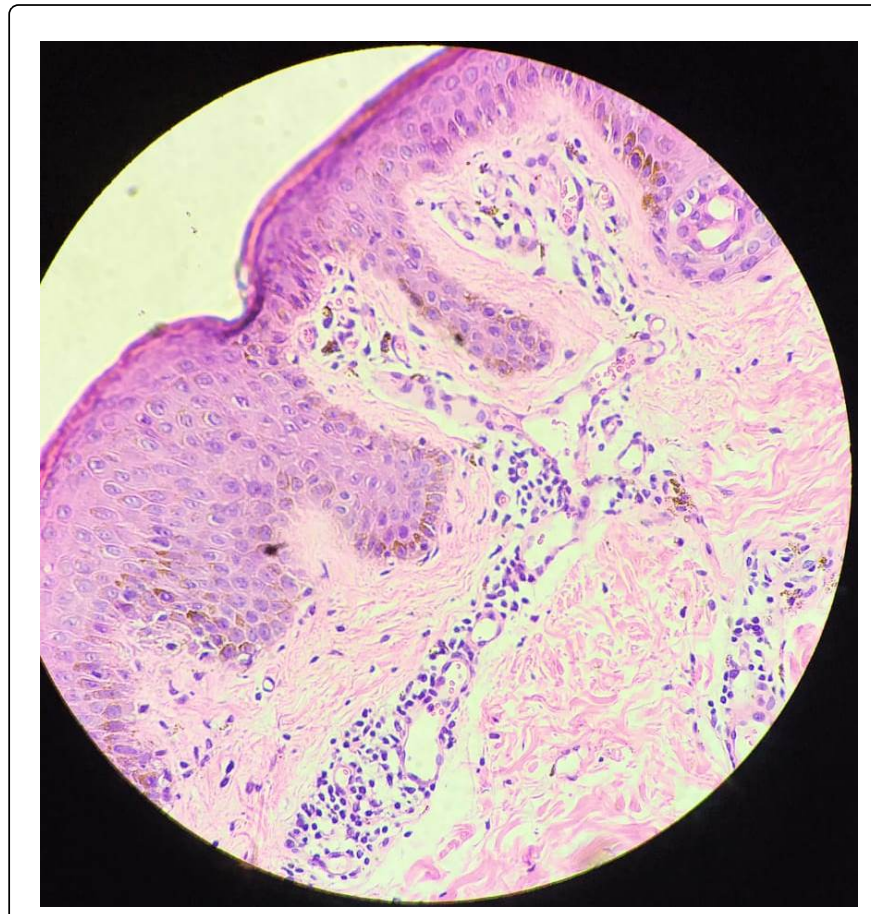

Figure 5: Histopathological picture of a biopsy taken from leg showing prominent basal melanization without pigmentary incontinence.

\section{Discussion}

LWNH is a rare pigmentary disorder characterized by linear and whorled hyperpigmented streaks along the Blaschko lines [1]. It occurs within a few weeks of life and progresses gradually for the next few years before stabilization. It is not preceded by inflammation or atrophy. There is sparing of the face, palms, soles, and mucus membranes.

The underlying cause of LMNH is poorly understood, it is thought to result from genetic mosaicism or chimerism [2,3]. LMNH generally occurs sporadically. Very rarely, familial cases have been described. Genetic studies suggest somatic mosaicism as a cause for LWNH with mosaic trisomy of 7, 14, 18, 20; X-chromosomal mosaicism has been reported $[3,4]$.

Various skeletal anomalies (facial and body asymmetry, brachydactyly), cardiovascular diseases (ventral septal defect, tetralogy of fallot) and central nervous system diseases (microcephaly, mental retardation, epilepsy) can be associated with $\mathrm{LWNH}[1,5]$.

Histopathologically, increase in pigmentation of the basal layer and prominence or vacuolization of melanocytes are seen. Pigmentary incontinence is usually, but not always absent [1]. Similar findings were noticed in our cases.

The differential diagnosis [5] includes Incontinentia Pigmenti (IP), epidermal nevus and hypomelanosis of Ito. In Incontinentia Pigmenti, cutaneous manifestations pass through vesicular, verrucous, whorls or streaks like hyperpigmentation and hypopigmented scar stages. Skin appendages are usually affected in this. Histopathologically, basal cell degeneration, pigmentary incontinence, dermal melanophages, and 
Citation: Saleh J, Vasicek B, Reserva J, Lake E, Speiser J (2019) Linear and Whorled Nevoid Hypermelanosis: A Rare Case Report. Dermatol Case Rep 4: 148.

Page 3 of 3

tissue eosinophilia are seen. Lack of these above features, rule out the possibility of IP in this case. Whereas epidermal nevi, usually appear during infancy as pigmented streaks along the Blaschko lines followed by verrucous stage which is histopathologically characterized by hyperkeratosis, acanthosis, papillomatosis and elongated rete ridges.

To the best of our knowledge, this is the second case of LWNH occurring in three successive generations being reported in the literature from India.

\section{References}

1. Metta AK, Ramachandra S, Sadath N, Manupati S (2011) Linear and whorled nevoid hypermelanosis in three successive generations. Indian J Dermatol Venereol Leprol 77: 403.
2. Akiyama M, Aranami A, Sasaki Y, Ebihara T, Sugiura M (1994) Familial linear and whorled nevoid hypermelanosis. J Am Acad Dermatol 30: 831-833.

3. Hartmann A, Hoffman UB, Hoehn H, Broecker EB, Hamm H (2004) Postnatal confirmation of prenatally diagnosed trisomy 20 mosaicism in a patient with linear and whorled nevoid hypermelanosis. Paediatr Dermatol 21: 636-641.

4. Sinha P, Chatterjee M, Singh KK, Sood A (2017) Linear and whorled nevoid hypermelanosis with depigmentation. Indian Dermatol Online J 8: 131-133.

5. Brar BK, Mahajan BB, Puri N (2009) Linear and whorled nevoid hypermelanosis. Indian Dermatol Online J 74: 512-513. 